\title{
NÃO SÓ, MAS TAMBÉM: A IGUALDADE DE GÊNERO MELHORA OS ÍNDICES ECONÔMICOS
}

\author{
Alyane Almeida de Araujo ${ }^{1}$
}

RESUMO: A demonstração de efeitos econômicos benéficos parece ter um efeito catalisador de mudanças em sociedades centradas na economia. Embora catalogado como direito social fundamental indisponível, o direito à proteção do mercado de trabalho da mulher (art. $7^{\circ}$, inciso XX, da Constituição da República Federativa do Brasil), ainda não foi plenamente concretizado. Através do método da análise de gênero do direito e da exposição de pesquisas de campo a respeito dos efeitos econômicos da igualdade de gênero no mercado de trabalho, esse estudo demonstrará que não somente, mas também há efeitos econômicos favoráveis que demonstram que a proteção da igualdade enquanto princípio jurídico também implica em busca da igualdade enquanto valor econômico agregado.

PALAVRAS-CHAVE: igualdade de gênero; mercado de trabalho; crescimento econômico.

\section{NOT ONLY, BUT ALSO: GENDER EQUALITY IMPROVES ECONOMIC RATES}

ABSTRACT: The demonstration of beneficial economic effects seems to have a catalytic effect of changes in societies centered on the economy. Although cataloged as an unavailable fundamental social right, the right to protection of the labor market for women (article 7, item XX, of the Constitution of the Federative Republic of Brazil), has not yet been fully realized. Through the method of gender analysis of law and the exposure of field research on the economic effects of gender equality in the labor market, this study will demonstrate that not only, but there are also favorable economic effects that demonstrate that the protection of equality as a legal principle it also implies the search for equality as an added economic value.

KEYWORDS: gender equality; labor market; economic growth.

\section{INTRODUÇÃO}

Por muito tempo foi propagada a ideia de que a contratação de mulheres representava maiores custos econômicos para a empresa e, por isso, deveria ser evitado. Atualmente, essa ideia se encontra superada, pois são arcados pelo Estado (ABRAMO, 2005, p. 53) os encargos financeiros decorrentes da licença do(a) trabalhador(a) responsável pelo acolhimento de um filho - fenômeno biológico ou jurídico (por tutela, curatela ou adoção) equivocadamente

\footnotetext{
${ }^{1}$ Doutoranda em Direitos Sociais (Université de Lille). Mestra em Direito Constitucional (UFRN). Especialista em Direito Internacional (UFRN). Especialista em Direito e Processo do Trabalho (UNIDERP). Graduada em Direito (UFRN). Contato: alyane@gmail.com.
} 
interpretado como naturalmente destinado a justificar a divisão sexual do trabalho de cuidados.

As desigualdades entre a mulher trabalhadora e o homem trabalhador é um fato socialmente verificável. Antiga e atual, essas desigualdades persistem em relação ao acesso, à permanência, à ascensão hierárquica e à segregação ocupacional nos países desenvolvidos, em desenvolvimento e não desenvolvidos.

Em várias regiões do mundo, em comparação com os homens, as mulheres têm menos chances de conseguir um emprego, ao mesmo tempo em que são mais suscetíveis ao desemprego quando conseguem uma vaga. Essas são apenas as diferenças na entrada e saída do mercado de trabalho. No que concerne ao período em que estão empregadas, as mulheres estão em posições hierárquicas mais inferiores e têm menores salários.

As estatísticas demonstram, ainda, que quando a mulher consegue um emprego de qualidade, com alto salário e posição hierárquica superior, ela ainda assume uma desigual distribuição de tarefas domésticas com o homem dentro do lar. A chance da mulher de participar do mercado de trabalho é $26 \%$ menor do que a do homem. A taxa de participação feminina na força de trabalho no mundo é de 50\%, em contraste com a taxa masculina de 76\%. Mas as mulheres não estão apenas em minoria no mercado de trabalho. (ILO, 2016. p. 1)

Apesar dessa estatística social desfavorável à mulher, repousa em princípio esplêndido o direito social da igualdade entre a mulher e o homem na maior parte dos países do globo terrestre - no Brasil, este princípio está consagrado no artigo $5^{\circ}$, inciso I, da Constituição da República Federativa do Brasil. A par disso, embora catalogado como direito social fundamental indisponível, o direito à proteção do mercado de trabalho da mulher (art. $7^{\circ}$, inciso XX, da Constituição da República Federativa do Brasil), ainda não foi plenamente concretizado.

A demonstração de efeitos econômicos benéficos parece ter um efeito catalisador de mudanças em sociedades centradas na economia. Portanto, para testar a hipótese, propomos realizar, através do método da análise de gênero do direito e da exposição de pesquisas de campo a respeito dos efeitos econômicos da igualdade de gênero no mercado de trabalho, um estudo apto a demonstrar que, não somente, mas também há efeitos econômicos favoráveis que demonstram que a proteção da igualdade enquanto princípio jurídico também implica em busca da igualdade enquanto valor econômico agregado. 


\section{AS DINÂMICAS SOCIAIS DAS DESIGUALDADES ENTRE A MULHER E O HOMEM NO MERCADO DE TRABALHO}

$\mathrm{Na}$ mais recente análise de dados compilados da Pesquisa Nacional por Amostra de Domicílios - Pnad, do Instituto Brasileiro de Geografia e Estatística - IBGE, entre 2016 e 2018, no Brasil quanto às profissões de engenheiros e arquitetos, médicos, professores, administradores e cientistas sociais, foi verificada uma grave desigualdade salarial entre mulheres e homens trabalhadores exercendo as mesmas funções, o que é ainda mais agravado com os marcadores de diferenças de raça. Segundo os autores, essa diferença pode ser explicada pela histórica discriminação de gênero e de raça que ainda se refletem em diferenças salariais (RIBEIRO; KOMATSU; MENEZES-FILHO, 2020, p. 3).

Por sua vez, o relatório "Mulheres no Trabalho: Tendências 2016" (tradução livre de "Women at Work: Trends 2016") da Organização Internacional do Trabalho - OIT sincroniza um aparato de informações a respeito dos países membros da OIT e das pesquisas que investigaram as causas e consequências das desigualdades entre a mulher e o homem trabalhor. O relatório evidencia que inexiste igualdade entre o homem e a mulher no mercado de trabalho, em escala mundial.

O Relatório aponta que os avanços foram ínfimos desde a Conferência Mundial da Mulher de Beijing de 1995, persistindo a desigualdade de gênero no mercado de trabalho do mundo inteiro, em relação às oportunidades, tratamento e resultados. Dentre os avanços dos últimos tempos citados no Relatório, estão os níveis de educação, por exemplo, onde as mulheres já são maioria, mas que não se reflete em salários e posições iguais aos dos homens. Assim, embora as mulheres tenham obtido um notável avanço nos índices de educação nas últimas décadas, isso não representou em melhoria da sua posição no trabalho em comparação com o homem.

A segregação setorial e hierárquica que a mulher sofre, aliada ao maior gasto de tempo com atividades não remuneradas, contribui para as diferenças salariais existentes entre o homem e a mulher. Essa segregação ocupacional e setorial influencia o aumento da desigualdade de gênero na quantidade e qualidade dos postos de trabalho. Ao mesmo tempo em que, em algumas ocupações (geralmente com menores remunerações) há uma grande quantidade de mulheres, em outras, elas estão sub-representadas. Foi verificado que há uma sobrerrepresentação da mulher em duas ocupações mais mal pagas, como "pessoal de 
secretariado, serviços e de vendas" e em "profissões não qualificadas" (ILO, 2016, p. xiv). Apenas 5\% dos chefes executivos de grandes empresas são mulheres. Há uma grande concentração das mulheres em ocupações de baixa remuneração (ILO, 2016, p. 25).

Homens estão em larga maioria nas funções de legisladores, funcionários superiores e gerentes, posições que além de bem remuneradas tem alto status social. Mulheres estão em maioria em atividades como vendedoras e professoras da educação infantil. Nos países não desenvolvidos ou em desenvolvimento, as mulheres são maioria em trabalho doméstico remunerado. Isso pode ser visto como um ciclo: enquanto mulheres e homens estão confinados em certas ocupações, estereótipos de gênero são fortalecidos em direção às aspirações profissionais, preferências e capacidades femininas e masculinas.

Do mesmo modo, isso também afeta a percepção que os empregadores têm sobre as habilidades e atitudes dos homens e das mulheres. Todo esse sistema desencoraja a mulher a escolher alguma ocupação que não seja "feminina" ou que não esteja de acordo com as "habilidades femininas". E as ocupações ditas femininas são as piores remuneradas, o que significa que um homem teria pouca motivação para quebrar o seu ciclo do estereótipo de profissões masculinas.

Trabalhos que demandam relações interpessoais ou envolvem trabalhos de cuidados são classificados como tipicamente femininos, sob a justificativa de que a mulher tem um atributo inato aos cuidados, tal como a tarefa que a mesma desempenha dentro do lar (BETTIO; VERASCHCAGINA, 2009, p. 12). Por outro lado, trabalhos que demandam força física ou cargos de decisão são considerados tipicamente masculinos (ANKER, 1998, p. 22). De forma similar, a racionalidade, em contraposição à emoção, é considerada uma característica masculina, o que torna as áreas tecnológicas e exatas predominantemente dos homens.

Um fenômeno interessante verificado nessa área da segregação é que os homens possuem vantagem salarial sobre as mulheres inclusive em setores ou ocupações altamente feminizadas, sendo esse fenômeno chamado de "escada rolante de vidro". O Relatório citou o exemplo da Austrália e Reino Unido, onde os homens que entram na profissão de enfermagem são mais propensos do que as mulheres a ocupar cargos superiores (ILO, 2016, p.52) . O mesmo acontecendo em setores da economia informal e também na economia formal cujos empregos são de baixo salário. 
Nessa perspectiva, o Relatório da OIT informa que a disparidade salarial de gênero pode ser dividida em componentes "explicáveis" e "inexplicáveis". Os componentes explicáveis são a segregação ocupacional e setorial, o tempo de trabalho e o exercício de trabalho formal e não formal. Os componentes inexplicáveis são a discriminação e outros fatores obscuros.

O Relatório da OIT denomina o que poderia ser chamado de "discriminação estatística”, onde os empregadores assumem que todas as mulheres esperam interromper suas carreiras, mostram menos interesse em treinamento para melhorar suas habilidades e são menos propensas a tomar posições hierárquicas superiores (ILO, 2016, p. 58).

O Relatório da OIT aponta, ainda, que existe uma disparidade salarial da maternidade (motherhood wage gap), caminhando ao lado da disparidade salarial de gênero (gender wage gap), onde se observa que a mulher ganha menos que o homem e, dentre as mulheres, aquelas que têm filhos ganham menos do que as que não têm filhos. Essa penalização salarial para as trabalhadoras que têm filhos é exatamente o oposto quando é o homem trabalhador que possui filhos. Pais trabalhadores, em contraste, costumam ganhar um salário maior do que os trabalhadores sem filhos (GRIMSHAW; RUBBERY, 2015, p. 28).

A diferença de tratamento é referida como salário bônus da paternidade (fatherhood wage premium), para fazer um paralelo com a penalidade sofrida pelas trabalhadoras mães (motherhood wage gap). A penalidade salarial, além da diferença salarial existente entre homens e mulheres, foi verificada em todas as partes do mundo. Mesmo depois que as crianças são crescidas, as penalidades do pagamento para a maternidade persistem (GRIMSHAW; RUBERY, 2015, p. 28).

Isso pode sugerir que as mães perdem salário devido ao tempo retirado do trabalho e as responsabilidades familiares e podem não ser capazes de ascender hierarquicamente mais tarde com a percepção de melhores salários - "they may become trapped in careers with limited pay promotion opportunities" (ILO, 2016, p. 58). O reforço salarial do homem pelo chamado "bônus da paternidade", pelo já descrito fenômeno verificado de aumento nos salários dos homens quando eles têm filhos (BUDIG, 2014, p. 26), agravam o sentimento de injustiça e desestimulam ainda mais a mulher a investir tempo na carreira profissional.

Tudo isso porque a motherhood wage gap reflete uma norma social segundo a qual é a mulher que deve sacrificar os ganhos e progressão na carreira para o parto e assistência à infância. $\mathrm{O}$ fato de as mulheres não poderem recuperar o curso de uma carreira profissional é 
indicativo da perpetuação de uma narrativa de que as mulheres são assalariadas secundárias e os homens o principal sustento da família. Consequentemente, essa penalidade para a maternidade levanta questões sobre a capacidade das sociedades de apoiarem a reprodução e a puericultura, bem como a igualdade de oportunidades e de tratamento no trabalho (ILO, 2016, p.65).

Essa é uma questão fundamental de reflexão sobre o papel e o impacto das políticas de trabalho e família no reconhecimento, redução e redistribuição do trabalho não remunerado doméstico e de cuidados, permitindo às mulheres entrar, permanecer e progredir na força de trabalho. Para encorajar os homens a dividir esses cuidados são essenciais normas jurídicas que instituam políticas de trabalho flexíveis; caso contrário, provavelmente não haverá uma efetiva mudança de papéis no seio da família, perpetuando as desigualdades de gênero no trabalho. Somente após a mudança de regras possibilitando e encorajando os homens com responsabilidades familiares a se submeter a jornadas flexíveis de trabalho e à licença parental, será possível observar mudança social.

O trabalho de cuidado envolve tarefas que as mulheres têm tradicionalmente desempenhado sem remuneração e essas habilidades, que são culturalmente consideradas como inatas para as mulheres, são subvalorizadas ou até mesmo esquecidas no impacto da economia nacional (OIT, 2012c; ILO, 2016, p. 69). Trabalho de cuidados não remunerados é definido como a prestação de serviços ou apoio às pessoas ou às casas sem qualquer recompensa monetária explícita. Atendimento de cuidado às pessoas inclui assistência, banho, alimentação (incluindo amamentação), interação com os membros da família (tais como brincar com as crianças, ajudando com lição de casa), acompanhamento nas consultas médicas e administração de medicamentos. Tarefas de cuidado com as casas incluem limpeza, compras para preparação de alimentos e cozinhar.

Há uma expectativa sociocultural de que, a partir de uma certa idade, mulheres jovens irão realizar a maioria das tarefas domésticas não remuneradas e trabalho de cuidado não remunerado (BOUDET et al., 2012; Apud ILO, 2016, p. 67). Essa divisão sexual precoce de trabalho segue as mulheres em suas vidas adultas. Uma pesquisa da OIT em 33 países mostrou que o número de meninas com idades entre 7-14 anos excedeu em muito o de meninos no desempenho de tarefas domésticas, o que muitas vezes inclui cuidar dos irmãos mais novos ou mais velhos. A proporção do Brasil é de duas meninas para cada menino; de Portugal é de duas e meia para cada um; e o Senegal é de quatro para um (ILO, 2016, p. 67). 
Em muitos países de renda baixa e média, o tempo gasto no trabalho não remunerado das mulheres e meninas é agravado pelo acesso inadequado à tecnologia básica e infraestrutura, incluindo água canalizada e tecnologia doméstica, em particular nas zonas rurais (RAZAVI, 2007; Apud ILO, 2016, p. 68). As crises econômicas também têm um impacto sobre a extensão e distribuição do trabalho de cuidado não remunerado. Uma pesquisa mostra que a perda de empregos e cortes de gastos públicos em benefícios e serviços sociais são tipicamente compensados pelo tempo adicional e esforço dedicado pelas mulheres em trabalhos de cuidado e outros trabalhos não remunerados, onde essas mulheres agem como uma "rede de segurança de último recurso" em crises econômicas (ELSON, 2014; UNRISD, 2010; Apud ILO, 2016, p. 69).

Além das crises econômicas, as mudanças demográficas, sociais e ambientais levam a uma maior demanda por serviços de cuidados pagos (ILO, 2016, p. 70). O Relatório aponta que, com um envelhecimento da população cada vez maior, a demanda por prestação de cuidados deve crescer ainda mais. Dentro de algumas regiões, as epidemias de saúde também têm contribuído para o aumento das exigências. Em países de baixa renda, tensões também são exacerbadas pela crescente pressão dos eventos relacionados à mudança climática, ao desmatamento e às crises de energia e alimentos, o que aumenta as horas gastas de trabalho não remunerado.

\section{IMPACTO ECONÔMICO DA CONCRETIZAÇÃO DO ART. $7^{\circ}, \mathrm{XX}$, CRFB}

O trabalho de cuidados exercido majoritariamente pela mulher ao longo do tempo, embora produtivo e útil para o mercado econômico, sempre foi (e continua sendo) ignorado. Marilyn Waring, parlamentar da Nova Zelândia, publicou em 1988 o livro "If Women Counted: a new feminist economics", onde defende categoricamente que o PIB ignora o trabalho não remunerado realizado pelas mulheres. Utiliza os exemplos de que, quando a comida é vendida, a atividade é "economicamente ativa" e, quando não, é "atividade econômica inativa". A única diferença aí é a presença ou a ausência de uma transação de mercado, embora a atividade seja idêntica - "Uma exclui as mulheres, enquanto a outra, não". (Apud KISHTAINY, 2013, p. 310). Essa "exclusão" ou “invisibilidade” ocasiona alguns efeitos adversos para a própria economia, que merecem ser mencionados.

Os custos da reprodução biológica, assim como aqueles relacionados à responsabilidade e ao trabalho de cuidados das pessoas, são custos externalizados, ou seja, são 
tomados como um dado na economia convencional, e considerados bens gratuitos fornecidos pela natureza (ABRAMO, 2005, p. 54). Mas esse "insumo natural" não é arcado pela sociedade como acontece, por exemplo, com os recursos naturais do meio ambiente, onde toda a geração presente e futura da humanidade arca com os seus prejuízos. Esses "custos" continuam sobrecarregando apenas as mulheres, cerca de metade da população mundial.

A atividade não remunerada de cuidado continua sem ser reconhecida em termos econômicos e ainda é considerada "invisível" aos olhos da sociedade. O esforço de apenas parte da população em manter e sustentar o encargo desse trabalho é potencializado pela falta de cobertura universal e de qualidade de serviços de guarda e acolhimento de crianças pequenas, como as creches.

Laís Abramo adverte sobre os efeitos desse fenômeno, destacando o uso da expressão "o cuidado é um recurso natural em vias de extinção", da economista Nancy Folbre, para chamar a atenção sobre a resistência das mulheres a seguir assumindo os custos da reprodução e sobre as consequências sociais desse comportamento, que já vem tomando dimensões preocupantes em alguns países europeus. A tensão provocada pela necessidade de conciliar esse esforço com as crescentes exigências derivadas da maior participação das mulheres no mundo do trabalho e da esfera pública em geral vem originando mudanças preocupantes no comportamento reprodutivo das mulheres, com importantes repercussões demográficas e sociais, cujo adiamento da maternidade ou opção por não ter filhos são algumas das manifestações desse comportamento (ABRAMO, 2005, p. 54-55).

Vê-se, nesse contexto, que a mulher está sendo triplamente sacrificada nas atuais circunstâncias: sofre discriminação na entrada no trabalho remunerado; quando entra, tem o trabalho remunerado em desvantagem com o homem (salários mais baixos, maior risco de desemprego, cargos hierarquicamente inferiores e segregados, p. ex.); e, independentemente de estar dentro ou fora do trabalho remunerado, tem o trabalho não remunerado de cuidado ignorado pela economia formal.

Atualmente, porém, para muito além da superação da representação econômica negativa dos custos de empregabilidade da mulher, e sem ainda existir a ponderação econômica do trabalho de cuidados, as pesquisas atuais evidenciam exatamente o oposto: a igualdade de gênero no mundo do trabalho é vantajoso do ponto de vista econômico. E ainda que a igualdade de gênero seja considerada um fim em si mesmo para qualquer sociedade que 
se pretenda democrática, torna-se útil também analisar os seus efeitos vantajosos para as sociedades que a promovem.

O Banco Mundial (BM) e a Organização de Cooperação e Desenvolvimento Econômico (OCDE) concluíram que a participação das mulheres na economia está ligada à redução da pobreza e ao crescimento do Produto Interno Bruto (PIB). ELBORG-WOITEK et al listaram os efeitos do impacto econômico decorrentes da igualdade de gênero no trabalho, a seguir elencados.

A primeira evidência encontrada foi a de que o wage gap (lacuna salarial) entre a mulher e o homem não é uma relação determinante quanto ao limite máximo do que pode ser pago pelo serviço prestado por ambos. Em vez disso, foi observado que não houve redução da média salarial dos homens quando o salário médio das mulheres foi elevado, o que demonstra que quando há redução da lacuna salarial entre ambos, o PIB per capita aumenta (ELBORGVOITEK, 2013, p. 4).

Outros estudos confirmaram a hipótese, ao demonstrar que a eliminação das disparidades de gênero no mercado de trabalho elevaria o PIB nos Estados Unidos em 5\%, no Japão em 9\%, nos Emirados Árabes Unidos em 12\%, na Índia em 27\% e no Egito em 34\% (ILO, 2016, p. 5). Os benefícios econômicos da igualdade de gênero são particularmente elevados nas sociedades que envelhecem rapidamente, em que o aumento da participação das mulheres no mercado de trabalho pode ajudar a compensar o impacto de uma diminuição da força de trabalho. Foi observado também que melhores oportunidades de emprego para as mulheres também podem contribuir para o aumento da lucratividade e produtividade no setor privado.

Após o rastreamento de 15 indicadores de igualdade de gênero em 95 países, foi constatado que, se as mulheres participarem da economia em um nível idêntico ao dos homens, isso poderia somar mais de US\$ 28 trilhões ou 26\% do Produto Interno Bruto (PIB) global anual em 2025, assumindo que se mantivesse o mesmo cenário econômico na data do estudo. "This impact is roughly equivalent to the size of the combined United States and Chinese economies today" (McKinsey Global Institute, 2015; Apud ILO, 2016, p. 5), ou seja, o impacto é equivalente ao tamanho das economias dos Estados Unidos e da China somadas.

Globalmente, 812 milhões das 865 milhões de mulheres que têm o potencial de contribuir para as suas economias nacionais através do emprego vivem em países emergentes e em desenvolvimento (ILO, 2016, p. 5). Contudo, é válido destacar que o mero crescimento 
econômico, sozinho, não assegura uma equitativa distribuição de ganhos entre os gêneros, conforme observado pela OIT (ILO, 2016, p. 28). É necessário que o Estado intervenha para promover as iguais oportunidades.

A inclusão de mulheres no mercado de trabalho formal contribuirá para aumentar a receita previdenciária em sociedades onde se verifica o rápido envelhecimento da população, devido a maior receita advinda de pessoas aptas a contribuírem para o sistema da seguridade social; a oportunidade para que mulheres recebam diretamente e controlem o seu salário contribui para o desenvolvimento econômico através de maior nível educacional das crianças, uma vez que as mulheres têm maior probabilidade de utilizar os seus salários investindo na educação dos filhos de ambos os sexos, o que gerará um círculo virtuoso para as meninas terem acesso à educação, capacitação e entrada no mercado de trabalho; e a redução da limitação jurídica para o acesso das mulheres a empréstimos, financiamentos, titularidade de empresas, dentre outros, ocasiona um maior nível de circulação de recursos, gerando competitividade e produção de lucros (ELBORG-VOITEK, 2013, p. 4-5).

De acordo com o Relatório do Banco Mundial sobre Mulheres, Negócios e Direito, 155 dos 173 países hoje têm pelo menos uma diferença legal entre homens e mulheres que restringe as oportunidades econômicas das mulheres. Em 54 países, as mulheres enfrentam cinco ou mais limitações (WB, 2015, p. 3).

As empreendedoras mulheres, que desenvolvem um negócio próprio sob conta e risco, também enfrentam dificuldades talvez ainda mais fortes. O Banco Mundial fez a cobertura em 173 economias para constatar que, em 155 países, há pelo menos uma barreira jurídica para a mulher, como, por exemplo, dificuldade para viajar, assinar um contrato, ter direitos de propriedade, abrir uma conta bancária ou registrar um negócio (WB, 2015, p. 2). O que há, de fato, é que em alguns países a própria lei é discriminatória contra as mulheres. Isso sem falar nos empecilhos indiretos, como, por exemplo, onde não há barreira legal expressa, mas ela deixa de viajar, por exemplo, em razão das responsabilidades familiares. No Relatório anterior, o Banco Mundial já havia exposto que mulheres que são chefes de família tem menores chances de acesso ao crédito para abrir um negócio do que os homens chefes de família (WB, 2011; Apud ILO, 2016, p. 5).

Mas além dos benefícios das mulheres como empreendedoras, foi observado também que as mulheres enquanto empregadas, em bases iguais aos homens, permite que as empresas façam melhor uso e aproveitamento dos talentos disponíveis, com grande possibilidade de 
inovações para o aumento da produtividade e redução de custos (ELBORG-VOITEK, 2013, p. 4-5).

Além disso, algumas empresas que tem mulheres na direção tiveram melhor performance e desempenho econômico, em produtos e serviços cujo mercado consumidor é maioria feminina (onde as mulheres nas direções tomaram decisões mais acertadas); foi constatado, ainda, que mulheres em conselhos diretivos tem menos propensão a fazer transações financeiras de alto risco no mercado financeiro (ELBORG-VOITEK, 2013, p. 4-5).

Empresas com gerências mais balanceadas quanto à representatividade de gênero tem melhores resultados econômicos (MCKINSEY, 2013; Apud ILO, p. 41), cujas vendas são maiores em $16 \%$ e o retorno em capital investido é maior em 26\% (CATALYST, 2013; Apud ILO, p. 41).

Essa evidência foi confirmada pela Thomson Reuters em 2014, onde, em um total de 1.843 empresas internacionais, evidenciou-se que a empresas com executivos homens e mulheres no topo tem uma performance melhor no retorno de resultados e no cometimento de menos erros de investimento (ILO, 2016, p. 41).

Enfim, nos últimos anos, pesquisas têm sido publicadas demonstrando o impacto positivo da diversidade de gênero em posições de gerência das empresas (MCKINSEY, 2013; CATALYST, 2013; CREDIT SUISSE, 2012; EUROPEAN COMMISSION, 2010; Apud ILO, 2016, p. 41). Há uma outra evidência a respeito da equidade de gênero que abre possibilidades para a economia crescer:

Com o rápido e crescente envelhecimento das populações, a economia do cuidado é comumente identificada como uma das duas principais fontes de futuro crescimento no emprego em ambos os países em desenvolvimento e desenvolvidos, a segunda fonte é a economia verde. (ILO, 2015r; Apud ILO, 2016, p. 89).

O investimento social em puericultura e programas de cuidados a deficientes e idosos cria um círculo virtuoso de redistribuição e redução do trabalho não remunerado, juntamente com a criação de trabalho remunerado que pode impulsionar o crescimento econômico, minimizar a transferência intergeracional da pobreza e aumentar a inclusão social (JENSON, 2009; Apud ILO, 2016, p. 89). Além disso, ao promover a criação de emprego, os investimentos sociais são particularmente eficazes como uma medida anticíclica em tempos de recessão económica (MOREL et al, 2009; Apud ILO, 2016, p. 89). 
Estudos de simulação encomendados pelos Estados Unidos sugerem que um investimento de US\$ 50 bilhões no setor de assistência social geraria 1,2 milhões de empregos na economia ou 8 em cada 10 novos empregos. Em contraste, o mesmo nível de expansão da infraestrutura no setor da construção criaria apenas 4 de 10 novos postos de trabalho (ANTONOPOULOUS et al., 2010; Apud ILO, 2016, p. 89), constatando a vantagem em investir naquele primeiro setor.

Pesquisa semelhante na Turquia estima que o investimento de 20,7 bilhões de liras turcas por ano (ou US\$ 9,5 bilhões, equivalente a 1,18\% do PIB em 2014) criaria 719.000 novos empregos no setor de cuidados (especificamente, cuidados na primeira infância e educação pré-escolar), em comparação com 290.000 novos postos de trabalho na construção e setores relacionados (İLKKARACAN et al., 2015; Apud ILO, p. 89). Além disso, os autores sugerem que os postos de trabalho no setor de cuidados proporcionariam mais empregos com benefícios de segurança social, como $85 \%$ dos postos de trabalho em cuidados com benefícios, em comparação com apenas 30\% dos trabalhos no setor de construção.

Há, por todo o exposto, uma inequívoca relação direta entre a redução da desigualdade de gênero no trabalho e o crescimento econômico. Dados demonstram que esse fenômeno dá um impulso à geração de lucros e à renda per capita. Essas foram as evidências encontradas pelas pesquisas, o que demonstra que, sob todos os ângulos de enfoque, a igualdade de gênero no mercado de trabalho é benéfica para a sociedade.

Amartya Sen já havia alertado para o efeito benéfico geral da igualdade de gênero para a toda sociedade, onde a ampliação das capacidades das mulheres não só aumenta a liberdade e o bem-estar das mulheres, mas também tem muitos outros efeitos sobre as vidas de todos, mulheres e homens, crianças e adultos.

Historicamente, fatores da vida pública (discriminação negativa de empregadores) e da vida privada (assunção das responsabilidades familiares) ocasionaram o alijamento da mulher em postos da economia informal e com maior probabilidade de baixa remuneração, além de influenciar a organização da família e a divisão do trabalho (ou "acumulação de trabalho", conforme nomenclatura de Amartya Sen).

A ONU identificou três fatores que contribuíram para estimular o crescimento e combater a pobreza entre as nações do Sul global que alcançaram maior progresso: "um estado pró-ativo do desenvolvimento, o aproveitamento dos mercados globais e a determinação da política social e da inovação". Segundo a ONU, a educação da mãe é mais 
importante para a sobrevivência infantil do que a renda familiar ou a riqueza e que as intervenções políticas têm um impacto maior onde os resultados da educação são inicialmente mais fracos. Isso tem implicações políticas profundas, potencialmente mudando a ênfase dos esforços para aumentar a renda das famílias para medidas para melhorar a educação das meninas.

Destaque-se, por fim, o $5^{\circ}$ Objetivo da Agenda 2030 cuja meta é atingir a igualdade de gênero. Esse objetivo, quando atingido, faz com que outros três objetivos da mesma Agenda sejam alcançados: redução da pobreza $\left(1^{\circ}\right)$, redução das desigualdades $\left(10^{\circ}\right)$ e a promoção de um crescimento econômico inclusivo e sustentável, produção de emprego e de trabalho sustentável para todos $\left(8^{\circ}\right)$.

A difícil questão da eficácia (existência) do direito internacional, porque desprovido de uma força policial independente e imparcial (entenda-se: sancionatória com efetividade) pode ter aportes teóricos e pistas de reflexão diferentes, como o que a nova metodologia de análise de gênero do direito tem feito (HENNETTE-VAUCHEZ; MöSCHEL; ROMAN, 2013).

A perspectiva de gênero no debate jurídico-científico francês é nova e inovadora e no Brasil está presente, viva e resistente; apesar dos pesares institucionais e certificadores. A primeira vez que um grupo de pesquisa tratou desse assunto na França foi por meio do Projeto REGINE - Recherches et Études sur le Genre et les Inégalités dans les Normes en Europe (Pesquisa e Estudos sobre Gênero e Desigualdades em Padrões na Europa).

O objetivo ambicioso do Projeto REGINE é refletir sobre a relação entre direito e gênero, organizada em três eixos: as desigualdades de gênero por meio da lei; desigualdade de gênero e lei francesa; e repensar a lei por meio do gênero. Já foram publicados livros sobre teoria geral, sob a égide do programa, como "Ce que le genre fait au droit" (HENNETTEVAUCHEZ, Stéphanie; MöSCHEL, Mathias; ROMAN, Diane, 2013); "Direito e gênero" (HENNETTE-VAUCHEZ, Stéphanie; PICHARD, Marc; ROMAN, Diane, 2014) e "Gênero e direito. Recursos educacionais" (HENNETTE-VAUCHEZ, Stéphanie; PICHARD, Marc; ROMAN, Diane, 2016), todos os títulos em tradução livre do original (seguido nas referências bibliográficas para quem se interessar em aprofundar o debate científico).

A aplicação da teoria geral sobre as ordens jurídicas comparativas de países específicos além da França começa a ser feita em estudos na Academia Francesa. Esta análise comparativa é particularmente importante para ultrapassar os limites jurídicos nacionais em 
termos de leitura do direito baseado no gênero, reformulando alguns conceitos jurídicos centrais de acordo com as problemáticas e limites que uma perspectiva de gênero venha a revelar.

Mas também e essencialmente porque o direito é e sempre foi retórico para apenas depois se tornar concreto e eficaz. Para dar um exemplo de direito concreto e dos seus efeitos retóricos após a sua modificação, finaliza-se essa breve exposição com a eficaz análise de Maria Sbalqueiro Lopes (2006), exposto em seguida a uma breve incursão teórica sobre o direito escrito da época.

Após a fase das normas impondo uma condição jurídica inferior à mulher (incapacidade civil, necessidade de autorização do marido para o trabalho, ausência de direitos políticos e educação limitada), além das diferenças fáticas produzidas socialmente enquanto inexistente a regulação de direitos trabalhistas (onde a mulher era considerada uma "meia-força" para recepção de salário, mas não para a exploração de uma extensa jornada de trabalho que chegava a $16 \mathrm{~h}$ diárias), adveio o momento em que a mulher passou a ser detentora de direitos de trabalhistas.

Esse momento ocorreu com uma exacerbação da "proteção" que tinham como pano de fundo dois principais fundamentos: resguardar a saúde da mulher, não enquanto si mesma, mas enquanto reprodutora biológica (desconsiderando que a maternidade já era uma opção e não um futuro inevitável); e resguardar a moral da mulher, não enquanto si mesma, mas enquanto peça fundamental da família (desconsiderando que, enquanto sujeito autônomo, a mulher poderia tomar suas decisões a respeito das suas próprias questões morais).

O Decreto $n^{\circ} 21.417 / 1932$ regulamentou as condições do trabalho das mulheres nos estabelecimentos industriais e comerciais. Logo no artigo $2^{\circ}$ foi vedado o trabalho da mulher no horário compreendido entre as $22 \mathrm{~h}$ até $5 \mathrm{~h}$, exceto caso fortuito ou força maior, em estabelecimentos onde só trabalhassem pessoas da família, as que diretamente estivessem incumbidas de tratamento de enfermos, em serviços de telefonia e radiofonia e em posto de direção (art. $3^{\circ}$ ). Além da proibição do trabalho noturno, também havia proibição do trabalho em minerações, construção civil e serviços perigosos e insalubres (art. $5^{\circ}$ ). A Constituição de 1934 manteve a proibição de trabalho em indústrias insalubres, o que permaneceu com a Constituição de 1946.

O Decreto-Lei $n^{\circ}$ 5.452/1943, que instituiu a Consolidação das Leis Trabalhistas, teve em sua redação original vários outros preceitos proibitivos. Passa-se a transcrever os 
dispositivos que não estão mais vigentes desde 1989 (Leis 7.855/89). A mulher não poderia executar horas-extras, a não ser por acordo, observado o limite de duas horas diárias de horas extras e de quarenta e oito horas semanais totais (art. 374), sendo obrigatória a comunicação à autoridade competente no prazo de quarenta e oito horas (art. 376).

Sobre esse tema, havia uma aclamada aceitação dessa norma, conforme Cristiane Maria Sbalqueiro Lopes, pois não foram poucos os estudiosos do direito do trabalho que, antes de 1988, aplaudiam o seu teor, pelo fato de a restrição às horas extras possibilitaria à mulher trabalhar fora de casa sem descurar de suas obrigações domésticas de "rainha do lar operário". O argumento de "preservação da família", ao atribuir à mulher a responsabilidade integral pelas obrigações familiares (cuidado dos filhos, tarefas domésticas, cuidado do marido), servia de fato à preservação da estrutura familiar da época (LOPES, 2006, p. 418), o que, em vez de proteger a mulher, a desprotegia ao legitimar a divisão injusta e não remunerada do trabalho no âmbito doméstico.

A proibição do trabalho noturno também foi estabelecida como regra, permanecendo o que havia no Decreto anterior (21.417/1932) a respeito das exceções, com um acréscimo: empregadas em casas de diversões, hotéis, restaurantes, bares e estabelecimentos congêneres (art. 379). O trabalho em obras de construção e mineradoras permaneceu proibido, assim como em atividades perigosas ou insalubres (art. 387).

Cabe destacar que não havia nenhuma norma com limitação de jornada, horas-extras, serviço noturno ou insalubre para o serviço de empregada doméstica. Em significante análise, Sbalqueiro Lopes explicita que a regulamentação do trabalho feminino não constitui reconhecimento ou acolhimento, pela ordem jurídica, das demandas veiculadas na perspectiva da igualdade de oportunidade entre os sexos, pois conferia ao direito do trabalho uma função predominantemente de controle social, cujo interesse maior era o de recordar que o verdadeiro lugar da mulher na sociedade de então era em casa, cuidando da família, leia-se, estrutura familiar patriarcal (LOPES, 2006, p. 410-411).

Mario de La Cueva ratifica essa posição, afirmando que não se deveria interpretar a "proteção" legal como sintoma de debilidade ou inferioridade da mulher, pois seus únicos propósitos representavam a necessidade de assegurar a sua saúde em benefício do futuro nacional e dar-lhes oportunidade de cuidar das suas famílias, sendo notável que entre os serviços perigosos estavam os suscetíveis de afetar a sua moralidade ou seus bons costumes (CUEVA, 1965, p.114). 
É paradigmática, nesse sentido, a norma jurídica expressa da CLT (também revogada em 1989), que autorizava o marido ou o pai pleitear a rescisão do contrato de trabalho da mulher, quando a sua continuação for suscetível de acarretar ameaça aos vínculos da família, perigo manifesto às condições peculiares da mulher ou prejuízo de ordem física ou moral para o menor (art. 446, § único, CLT).

Há quem defenda que esse dispositivo é capaz de desnudar o fato de que o bem jurídico que se procurou tutelar não consistia somente na preservação da família, mas principalmente na "proeminência do papel do varão à testa do vínculo matrimonial" (FREITAS JUNIOR, 1988, p. 213-214), isso porque as limitações jurídicas impostas à mulher vieram acompanhadas das aquisições jurídicas de direitos pelo homem enquanto detentor do real poder decisório na vida comum do casal.

Na obra de Arnaldo Sussekind ((2003, p. 666), é encontrada uma transcrição de um registro histórico da fala de um deputado, Augusto de Lima, em 1918, quando se discutia o projeto de Código do Trabalho no Brasil (que não chegou a ser aprovado), com um dispositivo que previa a possibilidade de trabalho da mulher casada sem prévia autorização do marido, onde é possível verificar que há a suspeita de devassidão moral das mulheres que trabalhassem sem a concordância do marido. ${ }^{2}$

Esse argumento moral de "proteção" da mulher legitimava a divisão sexual do trabalho no âmbito doméstico, onde a mulher poderia ser explorada sem limites, conservando a hierarquia patriarcal na família e a reprodução do poder que tornava o homem como uma entidade necessária para decidir a vida do "sexo frágil”. Aliás, a fragilidade da mulher serve como um relevante pretexto para reduzir-lhe os direitos e o poder econômico, pois já foi constatado que o falso cavalheirismo com que a maioria dos homens trata as mulheres é a compensação que lhe procuram oferecer por julgá-las seres inferiores e por isso necessitadas de proteção (CARDONE, 2011, p. 477).

\section{CONCLUSÕES}

\footnotetext{
2 “Este contrato traz a separação não sabida, não consentida pelo marido e, portanto, altamente suspeita, pondo em perigo o bom nome do lar. De uma mulher que se apresenta sem assistência do seu marido e até talvez, com oposição deste, o que se presume logo? O primeiro dever da mulher é estar de acordo com o seu marido em todos os casos. Em relação a esta mulher, que vai para uma fábrica, para um meio desconhecido, cuja moralidade o marido não conhece, cujo patrão pode ter anexos ou em outras partes outras indústrias que explora, a disposição é profundamente imoral" (SUSSEKIND, 2003, p. 666).
} 
Os efeitos da desigualdade de gênero atingem ambos, mulheres e homens, tanto quanto ao aspecto econômico, como quanto ao desenvolvimento intelectual de ambos, além das questões relacionadas à piora das condições de saúde da população (como a subnutrição infantil e mortalidade infantil) e das condições multifacetárias da vida política, econômica e social da sociedade.

E não se trata apenas de decisões limitadoras para a vida de todas as pessoas. Homens também planejam casar e ter filhos, tomando essa decisão para as suas vidas. Mas o casamento e as responsabilidades familiares não constituem uma limitação às suas decisões futuras de carreira profissional. No caso das mulheres, ao contrário, constituem. Além disso, foi comprovado o efeito salarial dos trabalhadores de ambos os sexos no caso do nascimento de filhos, através dos denominados fatherhood wage premium (bônus salarial da paternidade) e motherhood wage gap (penalidade salarial da maternidade). As mulheres passam a ganhar menos, ficando no extremo oposto da linha da lacuna salarial; em seguida estão as mulheres sem filhos, depois, os homens sem filhos, até chegar ao outro extremo da linha: os homens com filhos, que detém a maior média salarial. Mesmo depois que as crianças são crescidas, as penalidades do pagamento para a maternidade persistem (GRIMSHAW; RUBERY, 2015, p. 28).

A quebra dessas injustiças econômicas, com o acesso ao mercado formal com salários iguais aos dos homens torna as mulheres sujeitos efetivos de direitos de igualdade e de liberdade, contribui para o aumento da renda familiar, possibilita uma maior arrecadação tributária do Estado e aumenta a circulação de dinheiro na economia, beneficiando indivíduos, famílias, comunidades, empresas, Estado e economia como um todo.

O crescimento econômico inclusivo e igualitário, além de reduzir a pobreza e aumentar a renda per capita, possibilita maior investimento no capital humano. Como visto, estudos sobre benefícios de transferência de renda para mulheres demonstraram que elas priorizam investir na saúde e educação dos filhos, tornando a sociedade um ambiente melhor para se viver a longo prazo.

Todo o cabedal informativo a respeito dos dados expostos nas pesquisas divulgadas pelo Banco Mundial, Fundo Monetário Internacional e Organização Internacional do Trabalho, além de evidenciar o benéfico impacto econômico da igualdade de gênero no mercado de trabalho, conquistado a partir da modificação do papel tradicional tanto do homem como da mulher na sociedade e na família, requisito imprescindível para se alcançar a 
plena igualdade entre a mulher e o homem ( $§ 14$ do Preâmbulo da Convenção para a Eliminação de Todas as Formas de Discriminação contra a Mulher - CEDAW), serve para demonstrar que o crescimento econômico é potencializado quando ele também é inclusivo e igualitário.

\section{REFERÊNCIAS BIBLIOGRÁFICAS:}

ABRAMO, Laís; RANGEL, Marta. Negociação coletiva e igualdade de gênero na América Latina. Brasília - OIT SIT, 2005.

ABRAMO, Laís. A situação da mulher Latino-americana: O mercado de trabalho no contexto da reestruturação. In: DELGADO, Dirdice G.; CAPPELLIN, Paola; SOARES, Vera (org.). Mulher e Trabalho: Experiências de ação afirmativa. São Paulo: Boitempo Editorial, 2000. p. 111-134.

Questionando um mito: custos do trabalho de homens e mulheres.

Organização Internacional do Trabalho. Brasília: OIT, 2005.

ALEXY, Robert. Teoria dos Direitos Fundamentais. Tradução: Virgílio Afonso da Silva. São Paulo: Malheiros, 2008.

ANKER, R. Gender and jobs: Sex segregation of occupations in the world. Geneva: ILO, 1998.

BARROSO, Luís Roberto. Temas de Direito Constitucional. Tomo III. 2 ed. rev. Rio de Janeiro: Renovar, 2008.

. Interpretação e Aplicação da Constituição: Fundamentos de uma

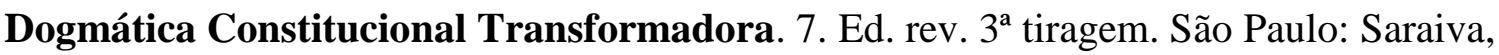
2009.

BETTIO, F.; VERASHCHAGINA, A. Gender segregation in the labour market: Root causes, implications and policy responses in the EU. Luxembourg: Publications Office of the European Union, 2009.

BUDIG, M.J. The fatherhood bonus and the motherhood penalty: Parenthood and the gender gap in pay. Washington DC: Third Way, 2014.

CARDONE, Marly A. A Mulher nas Constituições Brasileiras. In: PIOVESAN, Flavia; GARCIA, Maria (org.). Doutrinas Essenciais Direitos Humanos. Vol. IV. Grupos

Vulneráveis. São Paulo: Editora Revista dos Tribunais, 2011. p. 449-480. 
CUEVA, Mario De La. Panorama do direito do trabalho. Trad. Carlos Alberto Gomes Chiarelli. Porto Alegre: Sulina, 1965.

DWORKIN, Ronald. Levando os direitos a sério. 3. ed. São Paulo: Martins Fontes, 2010. FREITAS JUNIOR, Antonio Rodrigues de. O trabalho feminino no Brasil. Revista Jurídica do Trabalho, vol. 1, nº 3, Salvador, out-dez. 1988.

GRIMSHAW, D. What do we know about low wage work and low wage workers? Analysing the definitions, patterns, causes and consequences in international perspective. Conditions of Work and Employment Series nº 28. Geneva: ILO, 2011. HENNETTE-VAUCHEZ, Stéphanie; MöSCHEL, Mathias ; ROMAN, Diane. Ce que le genre fait au droit. Sous l'égide du programme REGINE. 1re édition. Dalloz : Paris, 2013. HENNETTE-VAUCHEZ, Stéphanie ; PICHARD, Marc ; ROMAN, Diane. La Loi et le Genre. Études critiques de droit français. CNRS Éditions : Paris, 2014. Genre et droit. Ressources pédagogiques. 1re édition. Dalloz : Paris, 2016.

ILO - International Labour Organization. Women at Work: Trends 2016. International Labour Office. Geneva: ILO, 2016. Disponível em:

<http://www.ilo.org/wcmsp5/groups/public/---dgreports/---dcomm/--publ/documents/publication/wcms_457317.pdf> Acesso: 15 set 2020.

LOPES, Cristiane Maria Sbalqueiro. Direito do Trabalho da mulher: da proteção à promoção. In: Cadernos Pagu. Campinas, n.26, p.405-430, 2006.

RIBEIRO, Beatriz Caroline; KOMATSU, Bruno Kawaoka; MENEZES-FILHO, Naercio. Diferenciais Salariais por Raça e Gênero para Formados em Escolas Públicas ou Privadas. Centro de Gestão e Políticas Públicas. Policy Paper nº 45. São Paulo: Insper, 2020. Disponível em: <https://www.insper.edu.br/wp-content/uploads/2020/07/Policy-Paper45.pdf> Acesso: 15 set 2020.

SARLET, Ingo Wolfgang. A Eficácia dos Direitos Fundamentais: uma Teoria Geral dos Direitos Fundamentais na Perspectiva Constitucional. 10 ed. rev. atual. e ampl. 2 tiragem. Porto Alegre: Livraria do Advogado, 2010a.

Neoconstitucionalismo e influência dos direitos fundamentais no direito privado: algumas notas sobre a evolução brasileira. In: SARLET, Ingo Wolfgang (org.) 
Constituição, 326 Direitos Fundamentais e Direito Privado. 3 ed. Rev. e ampl. Porto Alegre: Livraria do Advogado Editora, 2010b. p. 13-36.

SUSSEKIND, Arnaldo. Instituições de Direito do Trabalho. 21 ed. 1 vol. São Paulo: LTr, 2003. 